\title{
Review Article \\ Translational Significance of Selective Estrogen Receptor Modulators in Psychiatric Disorders
}

\author{
Mohammad M. Khan (D) \\ Department of Biochemistry and Molecular Biology, Faculty of Medicine, University of Zawia, P.O. Box 16418, Az-Zawiyah, Libya \\ Correspondence should be addressed to Mohammad M. Khan; mmkhan0@gmail.com
}

Received 18 June 2018; Revised 10 August 2018; Accepted 2 September 2018; Published 8 October 2018

Academic Editor: Małgorzata Kotula-Balak

Copyright (c) 2018 Mohammad M. Khan. This is an open access article distributed under the Creative Commons Attribution License, which permits unrestricted use, distribution, and reproduction in any medium, provided the original work is properly cited.

\begin{abstract}
Accumulating data from various clinical trial studies suggests that adjuvant therapy with ovarian hormones (estrogens) could be effective in reducing cognitive deficit and psychopathological symptoms in women with psychiatric disorders. However, estrogen therapy poses serious limitations and health issues including feminization in men and increased risks of thromboembolism, hot flashes, breast hyperplasia, and endometrium hyperplasia when used for longer duration in older women (aged $\geq 60$ years) or in women who have genetic predispositions. On the other hand, selective estrogen receptor modulators (SERMs), which may (or may not) carry some risks of hot flashes, thromboembolism, breast hyperplasia, and endometrial hyperplasia, are generally devoid of feminization effect. In clinical trial studies, adjuvant therapy with tamoxifen, a triphenylethylene class of SERM, has been found to reduce the frequency of manic episodes in patients with bipolar disorder, whereas addition of raloxifene, a benzothiophene class of SERM, to regular doses of antipsychotic drugs has been found to reduce cognitive deficit and psychological symptoms in men and women with schizophrenia, including women with treatment refractory psychosis. These outcomes together with potent neurocognitive, neuroprotective, and cardiometabolic properties suggest that SERMs could be the potential targets for designing effective and safer therapies for psychiatric disorders.
\end{abstract}

\section{Introduction}

Over the past twenty years, the role of estrogens in neuroprotection and cognition has been extensively investigated in both rodents and human subjects [1-6]. The results of these investigations suggest that estrogen treatment induces robust neuroprotection and improves memory and cognition in model animals of various neurological disorders [1-3]. Likewise, in postmenopausal women, estrogen therapy may improve one or more domains of cognition including verbal memory, speech, abstract reasoning, and information processing [3-9]. Based on these findings, psychiatrists have used estrogens to treat cognitive abnormalities in patients with schizophrenia and other mental illnesses [10-18]. The outcomes of these clinical trial studies suggest that estrogen therapy may improve certain aspects of cognition and also reduces psychiatric symptoms in postmenopausal women with schizophrenia and bipolar mania $[12-14,17,18]$. However, long-term estrogen therapy carries significant risks of thromboembolism, hot flashes, breast hyperplasia, and endometrial hyperplasia in older postmenopausal women or those having genetic predispositions [19-21]. Additionally, its use in men is restricted because of the feminization effect, as well as in young or adolescent girls because of hypersensitization issue $[19,20]$. Therefore, in recent years, efforts have been shifted toward selective estrogen receptor modulators (SERMs), which have shown potent estrogenic properties in the central nervous system (CNS). Although, SERMs may carry low risks of stimulating uterine or breast tissues but are devoid of feminization and hypersensitization effects [22-25].

SERMs are nonsteroidal estrogenic compounds derived from either the triphenylethylene or benzothiophene classes of compounds [23]. The members of the triphenylethylene class of SERMs include tamoxifen, clomiphene, toremifene, and GW5407, which are used primarily for the treatment/ prevention of breast cancer. The members of the benzothiophene class of SERMs include raloxifene, arzoxifene, 
bazedoxifene, and lasofoxifene, which are used primarily for the treatment of osteoporosis; however, raloxifene has also been approved for the treatment of breast cancer in highrisk postmenopausal women [23-25]. Intriguingly, an overwhelming body of evidence suggests that both classes of SERMs also have potent neurocognitive and neuroprotective properties. Studies performed in normal and model animals suggest that SERMs may improve memory and cognition and may increase neurogenesis and synaptic plasticity in the injured brain [26-32]. In addition, they reduce oxidative stress and neuroinflammation [33-40], which are considered potent etiological factors in many CNS disorders.

In recent years, several clinical trials have been conducted using SERMs as adjuvant drugs to investigate their effects on cognition and psychopathological symptoms in psychiatric disorders including bipolar disorder [41-43], schizophrenia [44-46], and Alzheimer's disease [47]. Two of the SERMs, namely, tamoxifen and raloxifene, have shown promising results in bipolar disorder and schizophrenia, respectively. However, raloxifene intervention in Alzheimer's disease was not effective [47]. In this review, translational significance of the outcome of tamoxifen and raloxifene augmentation trials in psychiatric disorders and the possible mechanisms of actions underneath their neurocognitive, neuroprotective, and cardiometabolic properties are discussed.

\section{Tamoxifen Augmentation Trials in Bipolar Disorder}

Bipolar disorder is a mental illness that brings severe high and low moods and changes in sleep, energy, thinking, and behavior. A manic episode occurs when patients have periods in which they feel overly excited and confident. They may show sometimes irritability and impulsive or reckless behavior and may experience delusions or hallucinations [48-50]. In addition, bipolar patients also display impairments in various cognitive domains including verbal memory, working memory, psychomotor speed, verbal fluency, attention, speed of information processing, executive function/reasoning, and problem solving $[48,51,52]$. These cognitive impairments can be identified in all phases of the disorder but are more frequent during manic episodes.

Treatment of bipolar disorder is challenging because the drugs that are used may be effective for a specific phase but may not be effective for other phases or they may even worsen the outcome of the illness [48, 53-57]. However, in the last $10-15$ years, several synthetic agents have been developed that are used for the treatment of different phases of bipolar disorder including acute mania, acute depression, and relapse prevention $[53,56,57]$. The advantage of using tamoxifen in augmentation therapy is that it can be effective in all phases of the disease, although evidence suggests that it has a more profound effect on manic episodes [41-43].

A preliminary study conducted by Bebchuk et al. showed that addition of $60-80 \mathrm{mg} / \mathrm{d}$ tamoxifen to regular doses of antidepressants significantly reduced the frequency of manic episodes in men and women with bipolar disorder [58]. Several subsequent studies also observed a significant reduction in acute mania by tamoxifen used at a dose of $40 \mathrm{mg} / \mathrm{d}$
[58-61]. However, one study could not reproduce their earlier findings in a large four-week randomized controlled trial performed using the same dose of tamoxifen [62]. The lack of tamoxifen effectiveness in their study might be due to its low dose and large sample size used. Contrary to this, several other randomized, double-blinded clinical trials conducted in women and children have reported significant reduction in the symptoms of mania by adjunct tamoxifen used at different doses starting from $40 \mathrm{mg} / \mathrm{d}$ up to $120 \mathrm{mg} / \mathrm{d}$ and the treatment was well tolerated for up to four weeks without inducing any serious adverse effect [63-65].

A meta-analysis while reviewing electronic data on all the randomized controlled trials also found that, in most cases, tamoxifen adjuvant therapy effectively reduced the frequency of manic episodes in bipolar patients [66]. This study suggests that tamoxifen can be considered an effective adjuvant in the treatment of manic bipolar patients. However, most of these clinical studies were piloted for short durations ranging from one to four weeks; therefore, conclusion regarding the efficacy and safety of tamoxifen use for longer periods and its effect on cognition warrants further studies with larger sample sizes and longer follow-up duration.

\section{Raloxifene Augmentation Trials in Schizophrenia}

Schizophrenia is a neurodevelopmental disorder that displays variable degree of cognitive deficit along with positive and negative symptoms of psychosis. The most common positive symptoms include hallucinations, delusions, and thought disorder, whereas most prevalent negative symptoms include apathy, blunted effect, and social withdrawal [67-69]. Cognitive deficit may be associated with a deficit in attention, working memory, verbal speech, executive function, and social cognition. In fact, cognitive deficit has been recognized as the potential risk factor in schizophrenia because it is generally present long before the onset of psychosis and becomes more severe as the illness advances [70-73]. Cognitive deficit adversely affects the ability of individuals to achieve academic standard, employment, and social status; therefore, improving cognition is considered a crucial therapeutic domain in integrating people with schizophrenia into the working environment and social life $[74,75]$.

Although over the last five-six decades, more than fifty antipsychotic drugs have been developed and used in various combinations, they have failed to improve cognition in schizophrenia. Also, their effectiveness to reduce psychopathological symptoms, especially negative symptoms, is far from convincing; instead, the risk of cardiometabolic morbidity and mortality is greatly increased after treatment is initiated [72, 75-82]. Additionally, some clinical trials performed using different supplementation strategies have not been very effective as they reduced mostly positive symptoms but not the negative symptoms and cognitive deficit [83-85]. Consequently, treating cognition and negative symptoms in schizophrenia is still an unresolved issue and the calls are growing for more effective therapies [74, 75, 78, 79, 83-85]. However, some clinical trial studies in which ovarian hormones (estrogens) were used as an adjuvant to antipsychotic 
drugs have shown promising results in schizophrenia. In one study, adjuvant estradiol treatment improved scores on comprehension of metaphoric speech without affecting verbal ability and word fluency [86]. Comprehension of metaphoric speech, a main feature of thought and language, is impaired in schizophrenia. In another study, adjuvant estradiol treatment effectively reduced PANSS positive, general, and total symptoms but did not reduce negative symptoms and cognitive deficit in women with treatment-resistant schizophrenia [13]. However, there is evidence suggesting that adjuvant estrogen treatment may improve certain aspects of cognition including memory, verbal fluency, and visual attention/psychomotor speed in chronic schizophrenia women of childbearing age [87]. These results are also supported by the clinical findings in which low circulating estrogen levels were associated with more sever negative symptoms and reduced cognitive performance, especially, verbal performance and executive functioning in women suffering from chronic schizophrenia [88]. Moreover, there is evidence suggesting that apart from positive, general, and total symptoms, adjuvant estrogen treatment may also reduce negative symptoms in women with schizophrenia [89-91]. Taken together; the above findings suggest that adjuvant estrogen therapy could be effective in reducing cognitive and psychopathological symptoms in schizophrenia. However, as discussed above, estrogen treatment may have some serious limitations and risks involved, which limits its use on a wider scale [19-21]. Consequently, in recent years, several clinical trials were conducted using raloxifene as adjuvant drug in treating cognition in schizophrenia, as discussed below. The results of these trial studies suggest that use of raloxifene is not only safer but may also lower the dose of antipsychotic drugs to achieve the same therapeutic outcome and may reduce side effects associated with long-term antipsychotic treatment.

Initial clinical trial studies with raloxifene adjuvant therapy were mainly performed in postmenopausal women with schizophrenia [44-46, 92-94]. In one study, two groups of patients treated with 60 and $120 \mathrm{mg} / \mathrm{d}$ doses of raloxifene as an adjuvant to antipsychotic drugs for 12 weeks showed significant reduction in PANSS total score and the general symptom score. The patients treated with higher raloxifene dose showed greater improvement [44]. Another placebocontrolled study in which postmenopausal women randomized to $60 \mathrm{mg} / \mathrm{d}$ raloxifene adjunct therapy showed significant reduction in the positive, negative, and general psychopathological symptoms after 12 weeks of treatment compared with women receiving placebo [45]. The same group recently confirmed their findings in a larger sample and longer duration (24 weeks) of treatment [46], which suggests that raloxifene augmentation is an effective strategy for treating positive, negative, and general psychological symptoms in postmenopausal women with schizophrenia. Other clinical trial studies have also reported similar reduction in symptoms after raloxifene adjuvant therapy $[92,93]$. However, in one study, Iranian postmenopausal women with schizophrenia, when treated with $120 \mathrm{mg} / \mathrm{d}$ raloxifene as an adjunct to risperidone $(6 \mathrm{mg} / \mathrm{d})$, showed improvement in positive symptoms only, whereas negative and general psychopathology symptoms did not improve [94].
Recently, raloxifene adjunct therapy has also been successfully tested in young men and women with schizophrenia including women with treatment-resistant psychosis $[95,96]$. In a randomized, double blind, placebo-controlled study, forty-six male schizophrenia patients were treated with either $120 \mathrm{mg} / \mathrm{d}$ raloxifene or placebo in addition to risperidone $(6 \mathrm{mg} / \mathrm{d})$ for eight weeks. The patients showed significant improvement in negative symptoms, general symptoms, and PANSS total score but not the positive symptoms [95]. Also in young women with treatment-resistant schizophrenia, treatment with $120 \mathrm{mg} / \mathrm{d}$ raloxifene as an adjuvant significantly reduced PANSS total and general symptom scores [96]. In other studies also, treatment with the same dose of raloxifene reduced PANSS general and positive symptom scores on hallucinatory behavior, agitation, and restlessness and also improved certain domains of cognition including attention, disorganized behavior, and sociooccupational functioning, and in some cases, therapeutic outcome was steady and maintained even after the dose of raloxifene was reduced to half $[97,98]$. These results suggest that raloxifene adjuvant therapy can improve certain aspects of social and nonsocial cognition. While a recent study did not observe any effect of raloxifene on mood and cognition in young schizophrenia women [96], other studies have indeed reported a positive effect of raloxifene adjuvant therapy on one or more domains of cognition.

In a 12-week randomized, placebo-controlled study, addition of $60 \mathrm{mg} / \mathrm{d}$ raloxifene to a regular antipsychotic dose improved verbal learning with no significant effect on longterm memory or recognition [99]. The authors also replicated this effect in a clinical case study in which a postmenopausal woman, treated with $60 \mathrm{mg} / \mathrm{d}$ raloxifene adjuvant, showed improvement in psychopathology and executive functions of cognition [100]. In another thirteen-week trial, addition of $120 \mathrm{mg} / \mathrm{d}$ raloxifene to their routine antipsychotic medications significantly improved attention/processing speed and memory in both men and women with schizophrenia [98]. Functional magnetic resonance imaging studies performed in male and female schizophrenia patients have shown that raloxifene treatment can also improve probabilistic association learning and emotional face recognition (a form of cognitive process that is impaired in schizophrenia) with concomitant increase in neuronal activity in the associated brain regions [101].

Recent meta-analyses performed on the outcome of all the raloxifene trial studies in schizophrenia concluded that raloxifene as an adjuvant is effective against all domains of schizophrenia psychosis, i.e., positive, negative, and general symptoms; however, the extent to which the symptom scores are reduced in each domain varies. Raloxifene may also improve cognition in both male and female schizophrenia patients including postmenopausal women [102-104]. This may be a very promising outcome because various imaging and histological studies suggest that negative symptoms and cognitive impairment are more strongly associated with the structural abnormalities in the brain than with positive symptoms [105-107]. While further clinical trials are needed to replicate the effect of raloxifene on cognition, initial evidence that raloxifene improves cognition and 
reduces negative symptoms even in treatment-resistant psychosis may suggest an improved structural plasticity and functional connectivity of the brain, which are otherwise reduced in schizophrenia patients [108-110].

\section{Mechanism of SERM Actions in CNS}

Data from various in vitro and in vivo animal studies suggests that SERMs have a peculiar mode of action. They can act as ER agonists in CNS tissues and as ER antagonists in non-CNS tissues. Acting as ER agonists, SERMs induce a number of estrogenic effects in the brain, which may regulate neuroprotection, memory and cognition, and the underlying brain connectivity [22, 26-32]. It is intriguing how various SERMs produce ER agonist or antagonist effects and how these effects relate to the clinical outcomes in various brain disorders. Whether a SERM is effective as an ER agonist or antagonist in a particular tissue depends upon several factors including the ER subtypes present, conformation of the ERs induced by the SERM, level, types, availability of coactivators and corepressors in the tissue, and types of coactivators and/or corepressors recruited to form the ER complex and the degree of interactions [22, 29, 111-114].

Although SERMs were initially thought to interact with classical ERs, that is, $\mathrm{ER} \alpha$ or $\mathrm{ER} \beta$, recent reports suggest that they also interact with transmembrane $G$ proteincoupled estrogen receptor-1 (GPER-1) in CNS [29, 111-114]. Thus, as of now, SERMs can interact with all the three subtypes of ERs in neurons and glia and can initiate both genomic and nongenomic signaling including activation of the cAMP/PKA, MAPK/ERKs, PI3K/Akt, JAK/STAT3, Wnt/ $\beta$ catenin/GSK3 $\beta$, and Nf-KB pathways [28, 29, 114-116]. All these signaling pathways regulate memory and cognition, neuroprotection, and brain regeneration process. However, the extent to which these signaling pathways are activated by different SERMs may differ, because of their differential affinity for ERs. It has been observed that the affinity of raloxifene is 4-fold higher (relative to estrogen) for ER $\alpha$ than $\operatorname{ER} \beta$, whereas the affinity of tamoxifen is similar for both receptors $[117,118]$.

After interacting with cell membrane ERs, SERMs can activate numerous cell signaling pathways as mentioned above and are shown in Figure 1. While that is the case in general, tamoxifen-induced inhibition of protein kinase $\mathrm{C}$ (PKC) is considered a prime reason for reduction in manic episodes in bipolar patients [41-43, 58, 60, 63]. However, the downstream effects of PKC inhibition may involve several other changes including alteration in synaptic plasticity/transmission, oxidative stress, neuroinflammation, and calcium and glutamate toxicity [28, 30, 33, 120-122]. Tamoxifen may reduce calcium toxicity directly by inhibiting calcium channels like raloxifene and estradiol [120-122]. However, whether calcium toxicity is the major cause of mania and whether its reduction by tamoxifen is a possible mechanism involved in its beneficial effects in bipolar patients remain to be investigated. Interestingly though, calcium channel-linked SNPs have been identified as risk alleles $[123,124]$ and certain types of calcium channel blockers have been found effective in reducing manic episodes in bipolar patients $[125,126]$. Further, animal studies have shown that both tamoxifen and raloxifene can prevent various receptor-mediated disruptions in prepulse inhibition [127], which is a measure of sensorimotor gating that is reduced in bipolar disorder, schizophrenia, and other psychiatric diseases [128-130].

Apart from PKC signaling involvement in the action of tamoxifen, several other signaling pathways are also activated by both tamoxifen and raloxifene as depicted in Figure 1. Raloxifene, in particular, has been studied extensively in CNS tissues, where it has been shown to activate the cAMP/PKA, MAPK/ERKs, PI3K/Akt, JAK/STAT3, $\mathrm{Wnt} / \beta$-catenin/GSK3 $\beta$, and Nf-KB pathways under various in vitro and in vivo experimental conditions [28-30, 114-116]. By activating these signaling pathways, raloxifene has been shown to regulate structural and functional plasticity underlying memory and cognition, neuroprotection, neurogenesis, oxidative stress, and neuroinflammation in the normal and model animals of CNS disorders [28-40]. Although tamoxifen also regulates most of these parameters, some evidence suggests that raloxifene may be more effective, probably, because of its high affinity for ER $\alpha$ compared to $\mathrm{ER} \beta$. However, the two ER subtypes may have different functional implications. In the neuroprotective and antiinflammatory properties of raloxifene, ER $\alpha$ may play a major role as evidence suggests that $\mathrm{ER} \alpha$ but not $\mathrm{ER} \beta$ is involved in the neuroprotective and anti-inflammatory properties of $17 \beta$-estradiol [119]. This has also been reflected in some in vitro and in vivo animal model studies, including our own, in which raloxifene has been found more effective than tamoxifen $[30,35]$. On the other hand, evidence suggests that $\mathrm{ER} \beta$ may play a major role in synaptic plasticity, memory, and cognition compared to $\operatorname{ER} \alpha$ [131-133]. In conclusion, the cognitive and psychopathological outcome of raloxifene adjuvant therapy in schizophrenia may be due to a combined effect of $\operatorname{ER} \alpha$ and $\operatorname{ER} \beta$ activation. However, further studies are needed to investigate the relative contribution of the two ER subtypes and also GPER-1 in the therapeutic effectiveness of raloxifene.

\section{SERMs Reduce Oxidative Stress and Neuroinflammatory Cues}

Mounting evidence suggests that prolonged psychological and social stresses can increase the levels of reactive oxygen species (ROS), proinflammatory chemokines, and cytokines produced by activated microglia [134-140]. Elevated ROS has been linked to several brain pathologies including the loss of parvalbumin-containing interneurons (reduced neurogenesis) and oxidation of lipids, nucleic acids, and proteins [141-147]. Similarly, excess of proinflammatory chemokines and cytokines such as IL- $1 \beta$, IL- 6 , and TNF $\alpha$ has been found to affect development, morphology, and the firing rate of neurons. It has been suggested that chronic inflammation of the brain can also lead to interneuron loss, NMDA receptor hypofunction, dopamine deregulation, and white matter abnormalities, consequently impairing cognitive and noncognitive behaviors including olfaction social interaction, reproduction, and energy balance. These behavioral 


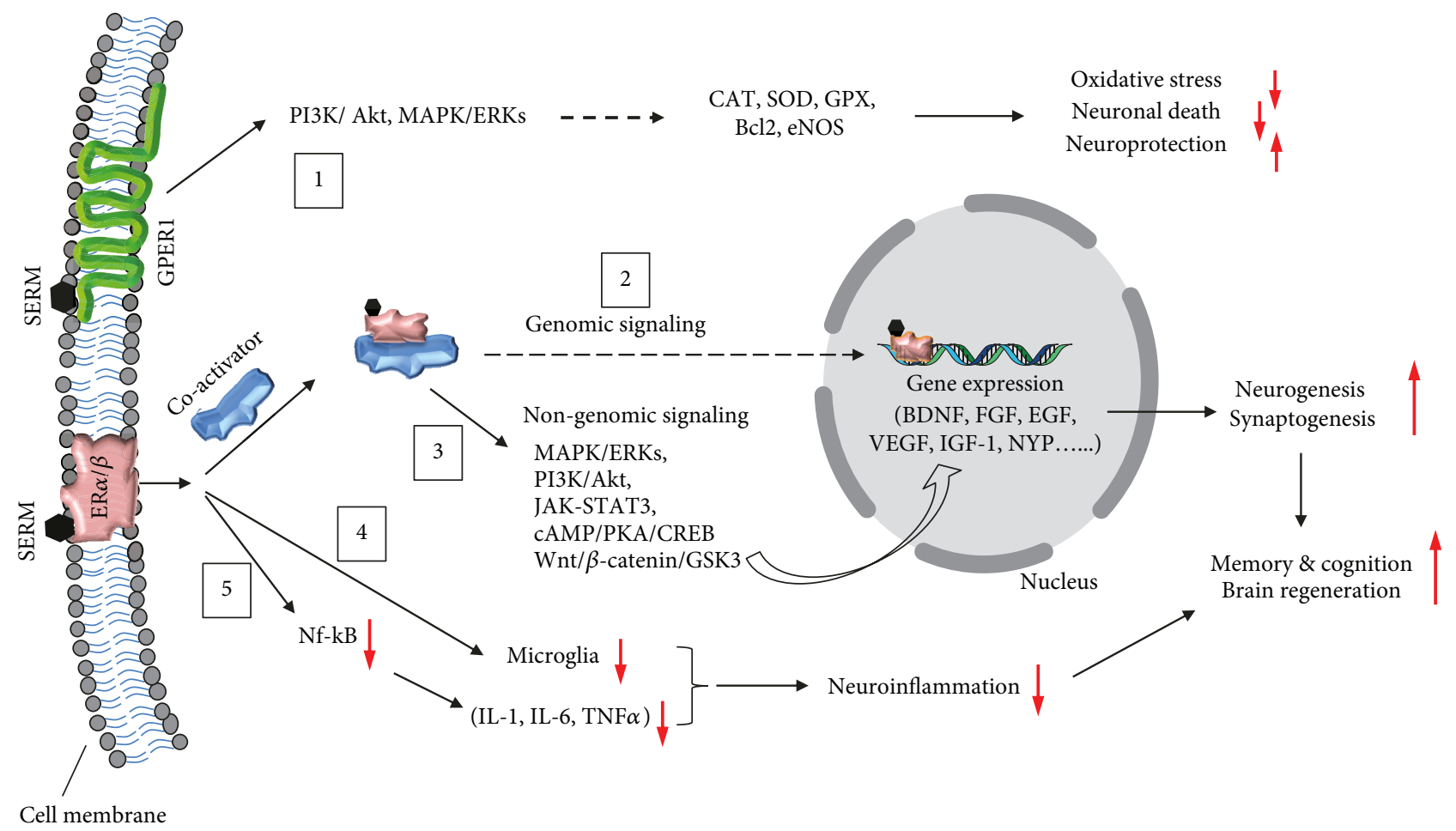

FIGURE 1: Possible signaling mechanisms of SERM actions in neurocognition and neuroprotection. Over the last few years, others and we have shown that SERMs can mediate their actions by initiating genomic (gene expression) and/or nongenomic signaling that involve kinases and phosphatases. In CNS tissues, SERMs can bind and activate both classical estrogen receptors- $\alpha$ and $\beta$ (ER $\alpha$ or ER $\beta$ ) as well as nonclassical transmembrane G protein-coupled ER (GPER1). Via agonist action at GPER1, SERMs can activate the PI3K/Akt and MAPK/ERK pathways (Figure 1, box 1), which have been shown to be involved in neuroprotection and reduction of oxidative stress and neuronal cell death by increasing the expression of antioxidant enzymes (CAT, SOD, GPx, and eNOS), Bcl2, and other trophic factors. Via agonist action at the classical ER $\alpha$ or ER $\beta$, SERMs can activate gene expression/genomic signaling (Figure 1, box 2) of various growth factors and proteins involved in synaptic plasticity, neurogenesis, memory, and cognition. SERMs can also enhance interaction of ER $\alpha$ or ER $\beta$ with MNAR/PELP1, a scaffold/coactivator protein highly expressed in neurons and astrocytes $[165,166]$. The resultant ER-MNAR/PELP1 complex can then initiate nongenomic signaling by activating the PI3K/Akt, MAPK/ERK, and Wnt/ $\beta$-catenin/GSK3 $\beta$ signaling pathways (Figure 1, box 3). These pathways have been shown to regulate neurogenesis, synaptogenesis, and cognitive behaviors in the normal and model animals of diseases. SERMs can reduce brain inflammation by acting on astroglia via ER $\alpha$ or ER $\beta$. They can reduce microglia proliferation (Figure 1, box 4) as well as production of inflammatory cytokines and chemokines including IL-1, IL-6, and TNF $\alpha$ via inhibition of nuclear factor-kappa-B (Nf-KB) transactivation (Figure 1, box 5). Inhibition of this pathway has been shown to induce neuroprotection and reduce neuronal cell death in various cellular and animal models of brain injury. Red arrows indicate increase (upward) or decrease (downward) in the magnitude of response by SERMs.

abnormalities together with the above-stated neurochemical and neuroanatomical pathologies have been reported in bipolar and schizophrenia patients [141, 146-151].

Reduction in oxidative stress and reduction in neuroinflammation are the two additional potential mechanisms of SERMs, which may contribute to their effectiveness in psychiatric disorders. A number of laboratories have investigated the antioxidative and anti-inflammatory effects of SERMs, in both in vitro and in vivo experimental studies [28, 31-40, 152-157]. While both tamoxifen and raloxifene have been shown to reduce oxidative stress by increasing expression of various proteins and enzymes involved in antioxidant defense [152-157], tamoxifen under certain conditions may in fact increase oxidative stress, although, by different mechanisms [158]. The antioxidative effect of raloxifene includes regulation of B-cell lymphoma regulator protein (Bcl-2), catalase, superoxide dismutase, and glutathione peroxidase gene expression and the level of reduced glutathione in the brain [33-40, 152-157]. Additionally, raloxifene has been shown to increase mRNA expression of apurinic/apyrimidinic endonuclease/redox factor-1 suggesting that it may protect against ROS-induced DNA damage. Increased ROS-induced DNA damage has been reported in the brain tissue of schizophrenia patients [159].

The anti-inflammatory effect of SERMs may be mediated by multiple pathways including the reduction in the levels of IL-6, IL-1 $\beta$, IP-10, and TNF $\alpha$ via suppression of microglia activation [35-39]. Additionally, raloxifene has been shown to block IL-1 $\beta$-induced Nf-KB transactivation (phosphorylation of p65) and expression of the CCL20 (chemokine (C-C motif) ligand-20) protein in the reactive astrocytes in an animal model of autoimmune encephalomyelitis, a chronic inflammatory condition [40]. Thus, raloxifene can be considered an effective antioxidative and anti-inflammatory agent, perhaps more potent than estrogen and tamoxifen [35]. 


\section{Safety of SERMs}

Data from various long-term clinical trial studies in which postmenopausal women were treated for breast cancer and osteoporosis suggests that SERM therapy carries some risks such as hot flashes, leg cramps, and venous thromboembolic events. Tamoxifen treatment may also carry the additional risks of hyper-proliferation of the uterine and endometrial tissues, and may be cognitive decline in older women, especially, when it is used for longer duration [25, 160-162]. However, these risks are observed in older women and after years of treatment $[25,160,161]$. These adverse effects have not been reported in young women or in postmenopausal women who did not have previous history of complications $[160,161]$. In conclusion, most of these analyses suggest that raloxifene has a favorable safety profile and its adverse effects, if any, can be reduced/minimized by changing dosing time and duration without affecting its therapeutic efficacy [162].

\section{Future of SERMs in Psychiatric Disorders}

Evidence for therapeutic effectiveness of SERMs in psychiatric disorders is emerging. SERMs can improve the clinical response of psychotropic drugs in patients with bipolar disorder and schizophrenia. While tamoxifen adjuvant therapy in bipolar patients requires additional studies on its safety for long-term use, raloxifene because of its favorable safety profile can be used safely in the long-term management of schizophrenia. Both of these SERMs have also been shown to prevent the development or delay the onset of cardiometabolic complications including diabetes, obesity, and atherosclerosis (reviewed in $[163,164]$ ), which are serious adverse effects often present from the early phase of illness in both schizophrenia and bipolar patients and become more severe after treatment with psychotropic drugs [80-82]. Therefore, use of SERMs may improve therapeutic efficacy of psychotropic drugs and the quality of life of psychiatric patients after treatment. Unlike tamoxifen, raloxifene has been found to improve cognition or delay the onset of cognitive decline in postmenopausal women on osteoporosis therapy. Therefore, further studies on the potential of raloxifene to improve cognitive behaviors would be very crucial because, currently, there are no effective drugs available to improve cognition in schizophrenia.

Additional advantages of using raloxifene in schizophrenia would be a negligible or no risk of feminization in men and hypersensitization in adolescent girls or younger women that may be observed with estrogens. Because of this advantage and noteworthy brain- and behaviorrepairing properties, raloxifene (or other more effective alike SERMs) provides an option for early intervention in schizophrenia, which might be more effective in correcting brain pathologies that lead to the development of cognitive deficit and psychosis in high-risk adolescents/individuals. Since evidence suggests that raloxifene adjuvant therapy may also reduce negative symptoms, which are more prominent in male compared to female schizophrenia patients, therefore, addition of raloxifene may enhance the potency of antipsychotic drugs to reduce negative symptoms more effectively in male schizophrenia patients.

\section{Conflicts of Interest}

The author declares that there is no conflict of interest regarding the publication of this manuscript.

\section{Acknowledgments}

Facilities provided by the Faculty of Medicine, University of Zawia, Libya, are gratefully acknowledged.

\section{References}

[1] L. M. Garcia-Segura, I. Azcoitia, and L. L. DonCarlos, "Neuroprotection by estradiol," Progress in Neurobiology, vol. 63, no. 1, pp. 29-60, 2001.

[2] I. Azcoitia, M. A. Arevalo, A. F. De Nicola, and L. M. GarciaSegura, "Neuroprotective actions of estradiol revisited," Trends in Endocrinology and Metabolism, vol. 22, no. 12, pp. 467-473, 2011.

[3] D. W. Brann, K. Dhandapani, C. Wakade, V. B. Mahesh, and M. M. Khan, "Neurotrophic and neuroprotective actions of estrogen: basic mechanisms and clinical implications," Steroids, vol. 72, no. 5, pp. 381-405, 2007.

[4] D. K. Hamson, M. M. Roes, and L. A. Galea, "Sex hormones and cognition: neuroendocrine influences on memory and learning," Comprehensive Physiology, vol. 6, no. 3, pp. 12951337, 2016.

[5] B. B. Sherwin, "Estrogen and cognitive functioning in women," Endocrine Reviews, vol. 24, no. 2, pp. 133-151, 2003.

[6] A. C. McCarrey and S. M. Resnick, "Postmenopausal hormone therapy and cognition," Hormones and Behavior, vol. 74, pp. 167-172, 2015.

[7] M. G. Cersosimo and E. E. Benarroch, "Estrogen actions in the nervous system: complexity and clinical implications," Neurology, vol. 85, no. 3, pp. 263-273, 2015.

[8] E. Hogervorst, "Estrogen and the brain: does estrogen treatment improve cognitive function?," Menopause International, vol. 19, no. 1, pp. 6-19, 2013.

[9] M. G. Baxter, M. T. Roberts, N. A. Gee, B. L. Lasley, J. H. Morrison, and P. R. Rapp, "Multiple clinically relevant hormone therapy regimens fail to improve cognitive function in aged ovariectomized rhesus monkeys," Neurobiology of Aging, vol. 34, no. 7, pp. 1882-1890, 2013.

[10] M. Cyr, F. Calon, M. Morissette, and T. Di Paolo, "Estrogenic modulation of brain activity: implications for schizophrenia and Parkinson's disease," Journal of Psychiatry \& Neuroscience, vol. 27, no. 1, pp. 12-27, 2002.

[11] U. Halbreich and L. S. Kahn, "Hormonal aspects of schizophrenias: an overview," Psychoneuroendocrinology, vol. 28, pp. 1-16, 2003.

[12] A. Gogos, A. M. Sbisa, J. Sun, A. Gibbons, M. Udawela, and B. Dean, "A role for estrogen in schizophrenia: clinical and preclinical findings," International Journal of Endocrinology, vol. 2015, Article ID 615356, 16 pages, 2015.

[13] J. Kulkarni, E. Gavrilidis, W. Wang et al., "Estradiol for treatment-resistant schizophrenia: a large-scale randomizedcontrolled trial in women of child-bearing age," Molecular Psychiatry, vol. 20, no. 6, pp. 695-702, 2015. 
[14] A. Riecher-Rössler, "Oestrogens, prolactin, hypothalamicpituitary-gonadal axis, and schizophrenic psychoses," Lancet Psychiatry, vol. 4, no. 1, pp. 63-72, 2017.

[15] J. Kulkarni, E. Gavrilidis, R. Worsley, and E. Hayes, "Role of estrogen treatment in the management of schizophrenia," CNS Drugs, vol. 26, no. 7, pp. 549-557, 2012.

[16] J. Kulkarni, E. Gavrilidis, R. Worsley, T. Van Rheenen, and E. Hayes, "The role of estrogen in the treatment of men with schizophrenia," International Journal of Endocrinology and Metabolism, vol. 11, no. 3, pp. 129-136, 2013.

[17] R. F. Zec and M. A. Trivedi, “The effects of estrogen replacement therapy on neuropsychological functioning in postmenopausal women with and without dementia: a critical and theoretical review," Neuropsychology Review, vol. 12, no. 2, pp. 65-109, 2002.

[18] A. Pompili, B. Arnone, and A. Gasbarri, "Estrogens and memory in physiological and neuropathological conditions," Psychoneuroendocrinology, vol. 37, no. 9, pp. 1379-1396, 2012.

[19] S. Rozenberg, J. Vandromme, and C. Antoine, "Postmenopausal hormone therapy: risks and benefits," Nature Reviews Endocrinology, vol. 9, no. 4, pp. 216-227, 2013.

[20] E. Barrett-Connor and C. A. Stuenkel, "Hormone replacement therapy (HRT) - risks and benefits," International Journal of Epidemiology, vol. 30, no. 3, pp. 423-426, 2001.

[21] E. P. Gurney, M. J. Nachtigall, L. E. Nachtigall, and F. Naftolin, "The Women's Health Initiative trial and related studies: 10 years later: a clinician's view," The Journal of Steroid Biochemistry and Molecular Biology, vol. 142, pp. 4-11, 2014.

[22] L. Zhao, K. O’Neill, and R. Diaz Brinton, “Selective estrogen receptor modulators (SERMs) for the brain: current status and remaining challenges for developing NeuroSERMs," Brain Research Reviews, vol. 49, no. 3, pp. 472493, 2005.

[23] P. Y. Maximov, T. M. Lee, and V. C. Jordan, "The discovery and development of selective estrogen receptor modulators (SERMs) for clinical practice," Current Clinical Pharmacology, vol. 8, no. 2, pp. 135-155, 2013.

[24] J. Arnott, S. Martinkovich, S. L. Planey, and D. Shah, “Selective estrogen receptor modulators: tissue specificity and clinical utility," Clinical Interventions in Aging, vol. 2014, pp. 1437-1452, 2014.

[25] S. Gizzo, C. Saccardi, T. S. Patrelli et al., "Update on raloxifene: mechanism of action, clinical efficacy, adverse effects, and contraindications," Obstetrical \& Gynecological Survey, vol. 68, no. 6, pp. 467-481, 2013.

[26] L. L. DonCarlos, I. Azcoitia, and L. M. Garcia-Segura, "Neuroprotective actions of selective estrogen receptor modulators," Psychoneuroendocrinology, vol. 34, pp. S113S122, 2009.

[27] M. A. Arevalo, M. Santos-Galindo, N. Lagunas, I. Azcoitia, and L. M. Garcia-Segura, "Selective estrogen receptor modulators as brain therapeutic agents," Journal of Molecular Endocrinology, vol. 46, no. 1, pp. R1-R9, 2011.

[28] C. Wakade, M. M. Khan, L. M. De Sevilla, Q. G. Zhang, V. B. Mahesh, and D. W. Brann, "Tamoxifen neuroprotection in cerebral ischemia involves attenuation of kinase activation and superoxide production and potentiation of mitochondrial superoxide dismutase," Endocrinology, vol. 149, no. 1, pp. 367-379, 2008.
[29] R. Abdelhamid, J. Luo, L. VandeVrede et al., "Benzothiophene selective estrogen receptor modulators provide neuroprotection by a novel GPR30-dependent mechanism," ACS Chemical Neuroscience, vol. 2, no. 5, pp. 256-268, 2011.

[30] M. M. Khan, C. Wakade, L. de Sevilla, and D. W. Brann, "Selective estrogen receptor modulators (SERMs) enhance neurogenesis and spine density following focal cerebral ischemia," The Journal of Steroid Biochemistry and Molecular Biology, vol. 146, pp. 38-47, 2015.

[31] D. A. Velázquez-Zamora, L. M. Garcia-Segura, and I. González-Burgos, "Effects of selective estrogen receptor modulators on allocentric working memory performance and on dendritic spines in medial prefrontal cortex pyramidal neurons of ovariectomized rats," Hormones and Behavior, vol. 61, no. 4, pp. 512-517, 2012.

[32] O. N. Kokiko, A. K. Murashov, and M. R. Hoane, "Administration of raloxifene reduces sensorimotor, and working memory deficits following traumatic brain injury," Behavioural Brain Research, vol. 170, no. 2, pp. 233-240, 2006.

[33] B. Yazğan, Y. Yazğan, I. S. Övey, and M. Naziroglu, "Raloxifene and tamoxifen reduce PARP activity, cytokine and oxidative stress levels in the brain and blood of ovariectomized rats," Journal of Molecular Neuroscience, vol. 60, no. 2, pp. 214-222, 2016.

[34] M. Ozgonul, A. Oge, E. D. Sezer, F. Bayraktar, and E. Y. Sozmen, "The effects of estrogen and raloxifene treatment on antioxidant enzymes in brain and liver of ovarectomized female rats," Endocrine Research, vol. 29, no. 2, pp. 183189, 2009.

[35] E. Arteaga, P. Villaseca, M. Bianchi, A. Rojas, and G. Marshall, "Raloxifene is a better antioxidant of low-density lipoprotein than estradiol or tamoxifen in postmenopausal women in vitro," Menopause, vol. 10, no. 2, pp. 142-146, 2003.

[36] G. Barreto, M. Santos-Galindo, Y. Diz-Chaves et al., "Selective estrogen receptor modulators decrease reactive astrogliosis in the injured brain: effects of aging and prolonged depletion of ovarian hormones," Endocrinology, vol. 150, no. 11, pp. 5010-5015, 2009.

[37] G. E. Barreto, M. Santos-Galindo, and L. M. Garcia-Segura, "Selective estrogen receptor modulators regulate reactive microglia after penetrating brain injury," Frontiers in Aging Neuroscience, vol. 6, 2014.

[38] Y. Ishihara, K. Itoh, A. Ishida, and T. Yamazaki, "Selective estrogen-receptor modulators suppress microglial activation and neuronal cell death via an estrogen receptor-dependent pathway," The Journal of Steroid Biochemistry and Molecular Biology, vol. 145, pp. 85-93, 2015.

[39] M. Cerciat, M. Unkila, L. M. Garcia-Segura, and M.-A. Arevalo, "Selective estrogen receptor modulators decrease the production of interleukin- 6 and interferon- $\gamma$-inducible protein- 10 by astrocytes exposed to inflammatory challengein vitro," Glia, vol. 58, no. 1, pp. 93-102, 2010.

[40] R. Li, W. Xu, Y. Chen et al., "Raloxifene suppresses experimental autoimmune encephalomyelitis and NF- $\mathrm{kB}$ dependent CCL20 expression in reactive astrocytes," PLoS One, vol. 9, no. 4, article e94320, 2014.

[41] A. Yildiz, S. Guleryuz, D. P. Ankerst, D. Ongur, and P. F. Renshaw, "Protein kinase $\mathrm{C}$ inhibition in the treatment of mania: a double-blind, placebo-controlled trial of tamoxifen," Archives of General Psychiatry, vol. 65, no. 3, pp. 255-263, 2008. 
[42] A. Yildiz, E. Vieta, S. Leucht, and R. J. Baldessarini, "Efficacy of antimanic treatments: meta-analysis of randomized, controlled trials," Neuropsychopharmacology, vol. 36, no. 2, pp. 375-389, 2011.

[43] A. Talaei, M. Pourgholami, H. Khatibi-Moghadam et al., "Tamoxifen: a protein kinase $\mathrm{C}$ inhibitor to treat mania: a systematic review and meta-analysis of randomized, placebo-controlled trials," Journal of Clinical Psychopharmacology, vol. 36, no. 3, pp. 272-275, 2016.

[44] J. Kulkarni, C. Gurvich, S. J. Lee et al., "Piloting the effective therapeutic dose of adjunctive selective estrogen receptor modulator treatment in postmenopausal women with schizophrenia," Psychoneuroendocrinology, vol. 35, no. 8, pp. 11421147, 2010.

[45] J. Usall, E. Huerta-Ramos, R. Iniesta et al., "Raloxifene as an adjunctive treatment for postmenopausal women with schizophrenia: a double-blind, randomized, placebo-controlled trial," The Journal of Clinical Psychiatry, vol. 72, no. 11, pp. 15521557, 2011.

[46] J. Usall, E. Huerta-Ramos, J. Labad et al., "Raloxifene as an adjunctive treatment for postmenopausal women with schizophrenia: a 24-week double-blind, randomized, parallel, placebo-controlled trial," Schizophrenia Bulletin, vol. 42, no. 2, pp. 309-317, 2016

[47] V. W. Henderson, T. Ala, K. L. Sainani et al., "Raloxifene for women with Alzheimer disease: a randomized controlled pilot trial," Neurology, vol. 85, no. 22, pp. 1937-1944, 2015.

[48] I. Grande, M. Berk, B. Birmaher, and E. Vieta, "Bipolar disorder," The Lancet, vol. 387, no. 10027, pp. 15611572, 2016.

[49] L. Sher and M. A. Oquendo, "Bipolar disorders in children and adolescents: dilemmas in their pathophysiology, diagnosis, and treatment," Minerva Pediatrica, vol. 60, no. 1, pp. 3739, 2008.

[50] K. N. Roy Chengappa and G. M. Goodwin, "Characterizing barriers, challenges and unmet needs in the management of bipolar disorder," Bipolar Disorders, vol. 7, no. s1, pp. 5-7, 2005.

[51] M. Vrabie, V. Marinescu, A. Talaşman, O. Tăutu, E. Drima, and I. Micluția, "Cognitive impairment in manic bipolar patients: important, understated, significant aspects," Annals of General Psychiatry, vol. 14, no. 1, p. 41, 2015.

[52] W. Duarte, R. Becerra, and K. Cruise, "The relationship between neurocognitive functioning and occupational functioning in bipolar disorder: a literature review," Europe's Journal of Psychology, vol. 12, no. 4, pp. 659-678, 2016.

[53] S. J. Mathew, H. K. Manji, and D. S. Charney, "Novel drugs and therapeutic targets for severe mood disorders," Neuropsychopharmacology, vol. 33, no. 9, pp. 2080-2092, 2008.

[54] G. S. Malhi, D. Adams, C. M. Cahill, S. Dodd, and M. Berk, "The management of individuals with bipolar disorder: a review of the evidence and its integration into clinical practice," Drugs, vol. 69, no. 15, pp. 2063-2101, 2009.

[55] A. Fagiolini, A. Coluccia, G. Maina et al., "Diagnosis, epidemiology and management of mixed states in bipolar disorder," CNS Drugs, vol. 29, no. 9, pp. 725-740, 2015.

[56] I. Grande and E. Vieta, "Pharmacotherapy of acute mania: monotherapy or combination therapy with mood stabilizers and antipsychotics?," CNS Drugs, vol. 29, no. 3, pp. 221227, 2015.
[57] A. M. Morsel, M. Morrens, and B. Sabbe, "An overview of pharmacotherapy for bipolar I disorder," Expert Opinion on Pharmacotherapy, vol. 19, no. 3, pp. 203-222, 2018.

[58] J. M. Bebchuk, C. L. Arfken, S. Dolan-Manji, J. Murphy, K. Hasanat, and H. K. Manji, "A preliminary investigation of a protein kinase $\mathrm{C}$ inhibitor in the treatment of acute mania," Archives of General Psychiatry, vol. 57, no. 1, pp. 95-97, 2000.

[59] J. Kulkarni, K. A. Garland, A. Scaffidi et al., "A pilot study of hormone modulation as a new treatment for mania in women with bipolar affective disorder," Psychoneuroendocrinology, vol. 31, no. 4, pp. 543-547, 2006.

[60] C. A. Zarate, J. B. Singh, P. J. Carlson et al., "Efficacy of a protein kinase $\mathrm{C}$ inhibitor (tamoxifen) in the treatment of acute mania: a pilot study," Bipolar Disorders, vol. 9, no. 6, pp. 561570, 2007.

[61] A. Yildiz, B. Aydin, N. Gökmen et al., "Antimanic treatment with tamoxifen affects brain chemistry: a double-blind, placebo-controlled proton magnetic resonance spectroscopy study," Biological Psychiatry: Cognitive Neuroscience and Neuroimaging, vol. 1, no. 2, pp. 125-131, 2016.

[62] J. Kulkarni, M. Berk, W. Wang et al., "A four week randomised control trial of adjunctive medroxyprogesterone and tamoxifen in women with mania," Psychoneuroendocrinology, vol. 43, pp. 52-61, 2014.

[63] A. Yildiz, S. Guleryuz, D. P. Ankerst, D. Öngür, and P. F. Renshaw, "Protein kinase $\mathrm{C}$ inhibition in the treatment of mania," Archives of General Psychiatry, vol. 65, no. 3, pp. 255-263, 2008.

[64] Z. Amrollahi, F. Rezaei, B. Salehi et al., "Double-blind, randomized, placebo-controlled 6-week study on the efficacy and safety of the tamoxifen adjunctive to lithium in acute bipolar mania," Journal of Affective Disorders, vol. 129, no. 1-3, pp. 327-331, 2011.

[65] E. Fallah, S. Arman, M. Najafi, and B. Shayegh, "Effect of tamoxifen and lithium on treatment of acute mania symptoms in children and adolescents," Iranian Journal of Child Neurology, vol. 10, no. 2, pp. 16-25, 2016.

[66] T. Miura, H. Noma, T. A. Furukawa et al., "Comparative efficacy and tolerability of pharmacological treatments in the maintenance treatment of bipolar disorder: a systematic review and network meta-analysis," The Lancet Psychiatry, vol. 1, no. 5, pp. 351-359, 2014.

[67] S. R. Kay, A. Fiszbein, and L. A. Opler, "The positive and negative syndrome scale (PANSS) for schizophrenia," Schizophrenia Bulletin, vol. 13, no. 2, pp. 261-276, 1987.

[68] K. T. Mueser and S. R. McGurk, "Schizophrenia," The Lancet, vol. 363, no. 9426, pp. 2063-2072, 2004.

[69] E. Walker, L. Kestler, A. Bollini, and K. M. Hochman, "SCHIZOPHRENIA: etiology and course," Annual Review of Psychology, vol. 55, no. 1, pp. 401-430, 2004.

[70] D. M. Barch and A. Ceaser, "Cognition in schizophrenia: core psychological and neural mechanisms," Trends in Cognitive Sciences, vol. 16, no. 1, pp. 27-34, 2012.

[71] R. S. Kahn and R. S. E. Keefe, "Schizophrenia is a cognitive illness: time for a change in focus," JAMA Psychiatry, vol. 70, no. 10, pp. 1107-1112, 2013.

[72] M. F. Green, W. P. Horan, and J. Lee, "Social cognition in schizophrenia," Nature Reviews Neuroscience, vol. 16, no. 10, pp. 620-631, 2015.

[73] D. C. Javitt and R. Freedman, "Sensory processing dysfunction in the personal experience and neuronal machinery of 
schizophrenia," American Journal of Psychiatry, vol. 172, no. 1, pp. 17-31, 2015.

[74] T. R. Insel, "Rethinking schizophrenia," Nature, vol. 468, no. 7321, pp. 187-193, 2010.

[75] M. J. Owen, A. Sawa, and P. B. Mortensen, "Schizophrenia," The Lancet, vol. 388, no. 10039, pp. 86-97, 2016.

[76] W. T. Carpenter and J. I. Koenig, "The evolution of drug development in schizophrenia: past issues and future opportunities," Neuropsychopharmacology, vol. 33, no. 9, pp. 20612079,2008

[77] W. T. Carpenter and J. M. Davis, "Another view of the history of antipsychotic drug discovery and development," Molecular Psychiatry, vol. 17, no. 12, pp. 1168-1173, 2012.

[78] S. Miyamoto, N. Miyake, L. F. Jarskog, W. W. Fleischhacker, and J. A. Lieberman, "Pharmacological treatment of schizophrenia: a critical review of the pharmacology and clinical effects of current and future therapeutic agents," Molecular Psychiatry, vol. 17, no. 12, pp. 1206-1227, 2012.

[79] S. Miyamoto, G. E. Duncan, C. E. Marx, and J. A. Lieberman, "Treatments for schizophrenia: a critical review of pharmacology and mechanisms of action of antipsychotic drugs," Molecular Psychiatry, vol. 10, no. 1, pp. 79-104, 2005.

[80] C. U. Correll, B. I. Joffe, L. M. Rosen, T. B. Sullivan, and R. T. Joffe, "Cardiovascular and cerebrovascular risk factors and events associated with second-generation antipsychotic compared to antidepressant use in a non-elderly adult sample: results from a claims-based inception cohort study," World Psychiatry, vol. 14, no. 1, pp. 56-63, 2015.

[81] C. U. Correll, J. Detraux, J. de Lepeleire, and M. de Hert, "Effects of antipsychotics, antidepressants and mood stabilizers on risk for physical diseases in people with schizophrenia, depression and bipolar disorder," World Psychiatry, vol. 14, no. 2, pp. 119-136, 2015.

[82] S. Leucht, A. Cipriani, L. Spineli et al., "Comparative efficacy and tolerability of 15 antipsychotic drugs in schizophrenia: a multiple-treatments meta-analysis," The Lancet, vol. 382, no. 9896, pp. 951-962, 2013.

[83] J. T. Coyle, "Schizophrenia: basic and clinical," Advances in Neurobiology, vol. 15, pp. 255-280, 2017.

[84] S. R. T. Veerman, P. F. J. Schulte, and L. de Haan, "Treatment for negative symptoms in schizophrenia: a comprehensive review," Drugs, vol. 77, no. 13, pp. 1423-1459, 2017.

[85] R. S. E. Keefe, R. W. Buchanan, S. R. Marder et al., "Clinical trials of potential cognitive-enhancing drugs in schizophrenia: what have we learned so far?," Schizophrenia Bulletin, vol. 39, no. 2, pp. 417-435, 2013.

[86] N. Bergemann, P. Parzer, S. Jaggy, B. Auler, C. Mundt, and S. Maier-Braunleder, "Estrogen and comprehension of metaphoric speech in women suffering from schizophrenia: results of a double-blind, placebo-controlled trial," Schizophrenia Bulletin, vol. 34, no. 6, pp. 11721181, 2008.

[87] Y. H. Ko, S. H. Joe, W. Cho et al., "Effect of hormone replacement therapy on cognitive function in women with chronic schizophrenia," International Journal of Psychiatry in Clinical Practice, vol. 10, no. 2, pp. 97-104, 2009.

[88] Y.-H. Ko, S.-H. Joe, W. Cho et al., "Estrogen, cognitive function and negative symptoms in female schizophrenia," Neuropsychobiology, vol. 53, no. 4, pp. 169-175, 2006.

[89] L. A. Lindamer, D. C. Buse, J. B. Lohr, and D. V. Jeste, "Hormone replacement therapy in postmenopausal women with schizophrenia: positive effect on negative symptoms?," Biological Psychiatry, vol. 49, no. 1, pp. 47-51, 2001.

[90] S. Akhondzadeh, A. A. Nejatisafa, H. Amini et al., "Adjunctive estrogen treatment in women with chronic schizophrenia: a double-blind, randomized, and placebo-controlled trial," Progress in Neuro-Psychopharmacology and Biological Psychiatry, vol. 27, no. 6, pp. 1007-1012, 2003.

[91] E. Ghafari, M. Fararouie, H. G. Shirazi, A. Farhangfar, F. Ghaderi, and A. Mohammadi, "Combination of estrogen and antipsychotics in the treatment of women with chronic schizophrenia: a double-blind, randomized, placebocontrolled clinical trial," Clinical Schizophrenia \& Related Psychoses, vol. 6, no. 4, pp. 172-176, 2013.

[92] H. Tharoor and A. Goyal, "Raloxifene trial in postmenopausal woman with treatment-resistant schizophrenia," Archives of Women's Mental Health, vol. 18, no. 5, pp. 741$742,2015$.

[93] J. Labad, L. Martorell, E. Huerta-Ramos et al., "Pharmacogenetic study of the effects of raloxifene on negative symptoms of postmenopausal women with schizophrenia: a doubleblind, randomized, placebo-controlled trial," European Neuropsychopharmacology, vol. 26, no. 10, pp. 1683-1689, 2016.

[94] G. Kianimehr, F. Fatehi, S. Hashempoor et al., "Raloxifene adjunctive therapy for postmenopausal women suffering from chronic schizophrenia: a randomized double-blind and placebo controlled trial," DARU Journal of Pharmaceutical Sciences, vol. 22, no. 1, p. 55, 2014.

[95] M. R. Khodaie-Ardakani, M. Khosravi, R. Zarinfard et al., "A placebo-controlled study of raloxifene added to risperidone in men with chronic schizophrenia," Acta Medica Iranica, vol. 53, no. 6, pp. 337-345, 2015.

[96] J. Kulkarni, E. Gavrilidis, S. M. Gwini et al., "Effect of adjunctive raloxifene therapy on severity of refractory schizophrenia in women: a randomized clinical trial," JAMA Psychiatry, vol. 73, no. 9, pp. 947-954, 2016.

[97] V. Shivakumar and G. Venkatasubramanian, "Successful use of adjuvant raloxifene treatment in clozapine-resistant schizophrenia," Indian Journal of Psychiatry, vol. 54, no. 4, p. 394, 2012.

[98] T. W. Weickert, D. Weinberg, R. Lenroot et al., "Adjunctive raloxifene treatment improves attention and memory in men and women with schizophrenia," Molecular Psychiatry, vol. 20, no. 6, pp. 685-694, 2015.

[99] E. Huerta-Ramos, R. Iniesta, S. Ochoa et al., "Effects of raloxifene on cognition in postmenopausal women with schizophrenia: a double blind, randomized, placebo-controlled trial," European Neuropsychopharmacology, vol. 24, no. 2, pp. 223-231, 2014.

[100] E. Huerta-Ramos, S. Ochoa, M. Roca, E. Miquel, and J. Usall, "The effect of raloxifene on symptoms and cognitive functioning in a postmenopausal schizophrenia patient: a case report," Archives of Women's Mental Health, vol. 18, no. 2, pp. 259-261, 2015.

[101] J. Kindler, C. S. Weickert, A. J. Skilleter, S. V. Catts, R. Lenroot, and T. W. Weickert, "Selective estrogen receptor modulation increases hippocampal activity during probabilistic association learning in schizophrenia," Neuropsychopharmacology, vol. 40, no. 10 , pp. 2388-2397, 2015

[102] X. M. Zhu, W. Zheng, X. H. Li et al., "Adjunctive raloxifene for postmenopausal women with schizophrenia: a metaanalysis of randomized, double-blind, placebo-controlled trials," Schizophrenia Research, vol. 197, pp. 288-293, 2018. 
[103] J. de Boer, M. Prikken, W. U. Lei, M. Begemann, and I. Sommer, "The effect of raloxifene augmentation in men and women with a schizophrenia spectrum disorder: a systematic review and meta-analysis," npj Schizophrenia, vol. 4, no. 1, p. 1, 2018.

[104] S. M. Heringa, M. J. H. Begemann, A. J. Goverde, and I. E. C. Sommer, "Sex hormones and oxytocin augmentation strategies in schizophrenia: a quantitative review," Schizophrenia Research, vol. 168, no. 3, pp. 603-613, 2015.

[105] M. Sanfilipo, T. Lafargue, H. Rusinek et al., "Volumetric measure of the frontal and temporal lobe regions in schizophrenia: relationship to negative symptoms," Archives of General Psychiatry, vol. 57, no. 5, pp. 471-480, 2000.

[106] B. Turetsky, P. E. Cowell, R. C. Gur, R. I. Grossman, D. L. Shtasel, and R. E. Gur, "Frontal and temporal lobe brain volumes in schizophrenia. Relationship to symptoms and clinical subtype," Archives of General Psychiatry, vol. 52, no. 12, pp. 1061-1070, 1995.

[107] S. Lui, W. Deng, X. Huang et al., "Association of cerebral deficits with clinical symptoms in antipsychotic-naive firstepisode schizophrenia: an optimized voxel-based morphometry and resting state functional connectivity study," American Journal of Psychiatry, vol. 166, no. 2, pp. 196205, 2009.

[108] Y. Quidé, R. W. Morris, A. M. Shepherd, J. E. Rowland, and M. J. Green, "Task-related fronto-striatal functional connectivity during working memory performance in schizophrenia," Schizophrenia Research, vol. 150, no. 2-3, pp. 468-475, 2013.

[109] K. C. Skåtun, T. Kaufmann, S. Tønnesen et al., "Global brain connectivity alterations in patients with schizophrenia and bipolar spectrum disorders," Journal of Psychiatry \& Neuroscience, vol. 41, no. 5, pp. 331-341, 2016.

[110] K. C. Skåtun, T. Kaufmann, N. T. Doan et al., "Consistent functional connectivity alterations in schizophrenia spectrum disorder: a multisite study," Schizophrenia Bulletin, vol. 43, no. 4, pp. 914-924, 2017.

[111] C. L. Smith and B. W. O'Malley, "Coregulator function: a key to understanding tissue specificity of selective receptor modulators," Endocrine Reviews, vol. 25, no. 1, pp. 45-71, 2004.

[112] Y. Shang and M. Brown, "Molecular determinants for the tissue specificity of SERMs," Science, vol. 295, no. 5564, pp. 2465-2468, 2002.

[113] V. Rossi, G. Bellastella, C. De Rosa et al., "Raloxifene induces cell death and inhibits proliferation through multiple signaling pathways in prostate cancer cells expressing different levels of estrogen receptor $\alpha$ and $\beta$," Journal of Cellular Physiology, vol. 226, no. 5, pp. 1334-1339, 2011.

[114] M. Bourque, M. Morissette, and T. di Paolo, "Raloxifene activates $G$ protein-coupled estrogen receptor 1/Akt signaling to protect dopamine neurons in 1-methyl-4-phenyl-1,2,3,6tetrahydropyridine mice," Neurobiology of Aging, vol. 35, no. 10, pp. 2347-2356, 2014.

[115] Y. Feng, J. Huang, Y. Ding, F. Xie, and X. Shen, “Tamoxifeninduced apoptosis of rat C6 glioma cells via PI3K/Akt, JNK and ERK activation," Oncology Reports, vol. 24, no. 6, pp. 1561-1567, 2010.

[116] I. K. Salgado, A. I. Torrado, J. M. Santiago, and J. D. Miranda, "Tamoxifen and Src kinase inhibitors as neuroprotective/ neuroregenerative drugs after spinal cord injury," Neural Regeneration Research, vol. 10, no. 3, pp. 385-390, 2015.
[117] M. Dutertre and C. L. Smith, "Molecular mechanisms of selective estrogen receptor modulator (SERM) action," The Journal of Pharmacology and Experimental Therapeutics, vol. 295, no. 2, pp. 431-437, 2000.

[118] G. G. Kuiper, J. G. Lemmen, B. O. Carlsson et al., "Interaction of estrogenic chemicals and phytoestrogens with estrogen receptor $\beta$," Endocrinology, vol. 139, no. 10, pp. 4252-4263, 1998.

[119] R. D. Spence, A. J. Wisdom, Y. Cao et al., "Estrogen mediates neuroprotection and anti-inflammatory effects during EAE through ERa signaling on astrocytes but not through ER $\beta$ signaling on astrocytes or neurons," The Journal of Neuroscience, vol. 33, no. 26, pp. 10924-10933, 2013.

[120] J. R. Kuo, C. C. Wang, S. K. Huang, and S. J. Wang, “Tamoxifen depresses glutamate release through inhibition of voltage-dependent $\mathrm{Ca} 2+$ entry and protein kinase $\mathrm{Ca}$ in rat cerebral cortex nerve terminals," Neurochemistry International, vol. 60, no. 2, pp. 105-114, 2012.

[121] Y. Huang, Y. L. Huang, B. Lai, P. Zheng, Y. C. Zhu, and T. Yao, "Raloxifene acutely reduces glutamate-induced intracellular calcium increase in cultured rat cortical neurons via inhibition of high-voltage-activated calcium current," Neuroscience, vol. 147, no. 2, pp. 334-341, 2007.

[122] X. Zhou, Z. Yang, L. Han et al., "Raloxifene neutralizes the adverse effects of glutamate on cultured neurons by regulation of calcium oscillations," Molecular Medicine Reports, vol. 12, no. 4, pp. 6207-6214, 2015.

[123] S. Heyes, W. S. Pratt, E. Rees et al., "Genetic disruption of voltage-gated calcium channels in psychiatric and neurological disorders," Progress in Neurobiology, vol. 134, pp. 36-54, 2015.

[124] P. F. Sullivan, M. J. Daly, and M. O'Donovan, "Genetic architectures of psychiatric disorders: the emerging picture and its implications," Nature Reviews Genetics, vol. 13, no. 8, pp. 537-551, 2012.

[125] P. G. Janicak, R. P. Sharma, G. Pandey, and J. M. Davis, "Verapamil for the treatment of acute mania: a double-blind, placebo-controlled trial," American Journal of Psychiatry, vol. 155, no. 7, pp. 972-973, 1998.

[126] A. Cipriani, K. Saunders, M. J. Attenburrow et al., “A systematic review of calcium channel antagonists in bipolar disorder and some considerations for their future development," Molecular Psychiatry, vol. 21, no. 10, pp. 13241332, 2016.

[127] A. Gogos and M. van den Buuse, "Comparing the effects of $17 \beta$-oestradiol and the selective oestrogen receptor modulators, raloxifene and tamoxifen, on prepulse inhibition in female rats," Schizophrenia Research, vol. 168, no. 3, pp. 634-639, 2015.

[128] G. K. Thaker, "Neurophysiological endophenotypes across bipolar and schizophrenia psychosis," Schizophrenia Bulletin, vol. 34, no. 4, pp. 760-773, 2008.

[129] H. K. Hamilton, T. J. Williams, J. Ventura et al., "Clinical and cognitive significance of auditory sensory processing deficits in schizophrenia," American Journal of Psychiatry, vol. 175, no. 3, pp. 275-283, 2018.

[130] M. A. Geyer, K. Krebs-Thomson, D. L. Braff, and N. R. Swerdlow, "Pharmacological studies of prepulse inhibition models of sensorimotor gating deficits in schizophrenia: a decade in review," Psychopharmacology, vol. 156, no. 2-3, pp. 117154, 2001. 
[131] J. L. Spencer-Segal, M. C. Tsuda, L. Mattei et al., "Estradiol acts via estrogen receptors alpha and beta on pathways important for synaptic plasticity in the mouse hippocampal formation," Neuroscience, vol. 202, pp. 131146, 2012.

[132] E. F. Rissman, A. L. Heck, J. E. Leonard, M. A. Shupnik, and J. A. Gustafsson, "Disruption of estrogen receptor $\beta$ gene impairs spatial learning in female mice," Proceedings of the National Academy of Sciences, vol. 99, no. 6, pp. 3996-4001, 2002.

[133] F. Liu, M. Day, L. C. Muñiz et al., "Activation of estrogen receptor-beta regulates hippocampal synaptic plasticity and improves memory," Nature Neuroscience, vol. 11, no. 3, pp. 334-343, 2008.

[134] S. Schiavone, S. Sorce, M. Dubois-Dauphin et al., "Involvement of NOX2 in the development of behavioral and pathologic alterations in isolated rats," Biological Psychiatry, vol. 66, no. 4, pp. 384-392, 2009.

[135] S. Salim, "Oxidative stress and psychological disorders," Current Neuropharmacology, vol. 12, no. 2, pp. 140-147, 2014.

[136] S. Schiavone, V. Jaquet, S. Sorce et al., "NADPH oxidase elevations in pyramidal neurons drive psychosocial stressinduced neuropathology," Translational Psychiatry, vol. 2, no. 5, p. e111, 2012.

[137] J. Wilhelm, R. Vytášek, J. Uhlík, and L. Vajner, “Oxidative stress in the developing rat brain due to production of reactive oxygen and nitrogen species," Oxidative Medicine and Cellular Longevity, vol. 2016, Article ID 5057610, 12 pages, 2016.

[138] E. Bouvier, F. Brouillard, J. Molet et al., "Nrf2-dependent persistent oxidative stress results in stress-induced vulnerability to depression," Molecular Psychiatry, vol. 22, no. 12, pp. 1701-1713, 2017.

[139] Y. Shao, G. Yan, Y. Xuan et al., "Chronic social isolation decreases glutamate and glutamine levels and induces oxidative stress in the rat hippocampus," Behavioural Brain Research, vol. 282, pp. 201-208, 2015.

[140] S. B. Powell, T. J. Sejnowski, and M. M. Behrens, "Behavioral and neurochemical consequences of cortical oxidative stress on parvalbumin-interneuron maturation in rodent models of schizophrenia," Neuropharmacology, vol. 62, no. 3, pp. 1322-1331, 2012.

[141] G. E. Hardingham and K. Q. Do, "Linking early-life NMDAR hypofunction and oxidative stress in schizophrenia pathogenesis," Nature Reviews Neuroscience, vol. 17, no. 2, pp. 125-134, 2016.

[142] U. Sertan Copoglu, O. Virit, M. Hanifi Kokacya et al., "Increased oxidative stress and oxidative DNA damage in non-remission schizophrenia patients," Psychiatry Research, vol. 229, no. 1-2, pp. 200-205, 2015.

[143] S. Şimşek, S. Gençoğlan, T. Yüksel, I. Kaplan, R. Alaca, and H. Aktaş, "Oxidative stress and DNA damage in untreated first-episode psychosis in adolescents," Neuropsychobiology, vol. 73, no. 2, pp. 92-97, 2016.

[144] M. M. Khan, D. R. Evans, V. Gunna, R. E. Scheffer, V. V. Parikh, and S. P. Mahadik, "Reduced erythrocyte membrane essential fatty acids and increased lipid peroxides in schizophrenia at the never-medicated first-episode of psychosis and after years of treatment with antipsychotics," Schizophrenia Research, vol. 58, no. 1, pp. 1-10, 2002.
[145] M. A. Calcia, D. R. Bonsall, P. S. Bloomfield, S. Selvaraj, T. Barichello, and O. D. Howes, "Stress and neuroinflammation: a systematic review of the effects of stress on microglia and the implications for mental illness," Psychopharmacology, vol. 233, no. 9, pp. 1637-1650, 2016.

[146] A. Borsini, P. A. Zunszain, S. Thuret, and C. M. Pariante, "The role of inflammatory cytokines as key modulators of neurogenesis," Trends in Neurosciences, vol. 38, no. 3, pp. 145-157, 2015.

[147] D. Inta, A. Meyer-Lindenberg, and P. Gass, "Alterations in postnatal neurogenesis and dopamine dysregulation in schizophrenia: a hypothesis," Schizophrenia Bulletin, vol. 37, no. 4, pp. 674-680, 2011.

[148] M. A. Shelton, J. T. Newman, H. Gu et al., "Loss of microtubule-associated protein-2 immunoreactivity linked to dendritic spine loss in schizophrenia," Biological Psychiatry, vol. 78, no. 6, pp. 374-385, 2015.

[149] S. Najjar and D. M. Pearlman, "Neuroinflammation, and white matter pathology in schizophrenia: systematic review," Schizophrenia Research, vol. 161, no. 1, pp. 102-112, 2015.

[150] N. Müller, E. Weidinger, B. Leitner, and M. J. Schwarz, "The role of inflammation in schizophrenia," Frontiers in Neuroscience, vol. 9, 2015.

[151] K. P. Good and R. L. Sullivan, "Olfactory function in psychotic disorders: insights from neuroimaging studies," World Journal of Psychiatry, vol. 5, no. 2, pp. 210-221, 2015.

[152] A. Oge, E. D. Sezer, M. Ozgönül, F. Bayraktar, and E. Y. Sözmen, "The effects of estrogen and raloxifene treatment on the antioxidant enzymes and nitrite-nitrate levels in brain cortex of ovariectomized rats," Neuroscience Letters, vol. 338, no. 3, pp. 217-220, 2003.

[153] G. Armagan, L. Kanit, C. M. Terek, E. Y. Sozmen, and A. Yalcin, "The levels of glutathione and nitrite-nitrate and the expression of Bcl-2 mRNA in ovariectomized rats treated by raloxifene against kainic acid," The International Journal of Neuroscience, vol. 119, no. 2, pp. 227-239, 2009.

[154] S. Konyalioglu, G. Durmaz, and A. Yalcin, "The potential antioxidant effect of raloxifene treatment: a study on heart, liver and brain cortex of ovariectomized female rats," Cell Biochemistry and Function, vol. 25, no. 3, pp. 259-266, 2007.

[155] S. Ozgocmen, H. Kaya, E. Fadillioglu, and Z. Yilmaz, "Effects of calcitonin, risedronate, and raloxifene on erythrocyte antioxidant enzyme activity, lipid peroxidation, and nitric oxide in postmenopausal osteoporosis," Archives of Medical Research, vol. 38, no. 2, pp. 196-205, 2007.

[156] U. Korucuoğlu, B. Ciftçi, O. Gülbahar et al., "Assessment of protein oxidation in women using raloxifene," Molecular and Cellular Biochemistry, vol. 290, no. 1-2, pp. 97-101, 2006.

[157] Y. Yazğan and M. Nazıroğlu, "Ovariectomy-induced mitochondrial oxidative stress, apoptosis, and calcium ion influx through TRPA1, TRPM2, and TRPV1 are prevented by $17 \beta$-estradiol, tamoxifen, and raloxifene in the hippocampus and dorsal root ganglion of rats," Molecular Neurobiology, vol. 54, no. 10, pp. 7620-7638, 2017.

[158] F. Denk, L. M. Ramer, E. L. K. S. Erskine et al., "Tamoxifen induces cellular stress in the nervous system by inhibiting cholesterol synthesis," Acta Neuropathologica Communications, vol. 3, no. 1, p. 74, 2015. 
[159] A. Yalcin, L. Kanit, G. Durmaz, S. Sargin, C. H. Terek, and B. Tanyolac, "Altered level of apurinic/apyrimidinic endonuclease/redox factor-1 (APE/REF-1) mRNA in the hippocampus of ovariectomized rats treated by raloxifene against kainic acid," Clinical and Experimental Pharmacology \& Physiology, vol. 32, no. 8, pp. 611-614, 2005.

[160] C. L. Deal and M. W. Draper, "Raloxifene: a selective estrogen-receptor modulator for postmenopausal osteoporosis - a clinical update on efficacy and safety," Womens Health, vol. 2, no. 2, pp. 199-210, 2006.

[161] A. Cranney and J. D. Adachi, "Benefit-risk assessment of raloxifene in postmenopausal osteoporosis," Drug Safety, vol. 28, no. 8, pp. 721-730, 2005.

[162] H. Ando, T. Otoda, H. Ookami et al., "Dosing timedependent effect of raloxifene on plasma plasminogen activator inhibitor-1 concentrations in post-menopausal women with osteoporosis," Clinical and Experimental Pharmacology \& Physiology, vol. 40, no. 3, pp. 227-232, 2013.

[163] B. Xu, D. Lovre, and F. Mauvais-Jarvis, "Effect of selective estrogen receptor modulators on metabolic homeostasis," Biochimie, vol. 124, pp. 92-97, 2016.

[164] M. M. Khan, "Neurocognitive, neuroprotective, and cardiometabolic effects of raloxifene: potential for improving therapeutic outcomes in schizophrenia," CNS Drugs, vol. 30, no. 7, pp. 589-601, 2016.

[165] M. M. Khan, M. Hadman, C. Wakade et al., "Cloning, expression, and localization of MNAR/PELP1 in rodent brain: colocalization in estrogen receptor-alpha- but not in gonadotropin-releasing hormone-positive neurons," Endocrinology, vol. 146, no. 12, pp. 5215-5227, 2005.

[166] M. M. Khan, M. Hadman, L. M. De Sevilla et al., "Cloning, distribution, and colocalization of MNAR/PELP1 with glucocorticoid receptors in primate and nonprimate brain," Neuroendocrinology, vol. 84, no. 5, pp. 317-329, 2006. 


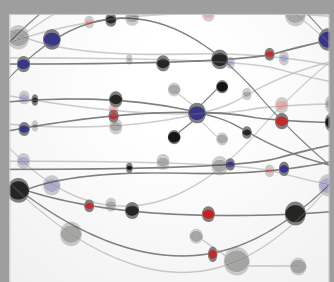

The Scientific World Journal
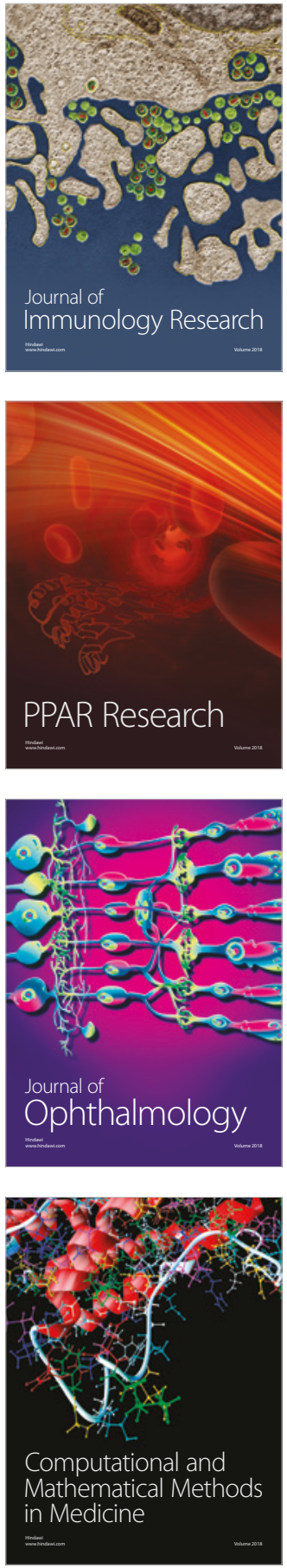

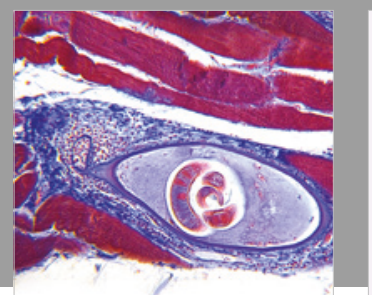

Gastroenterology Research and Practice

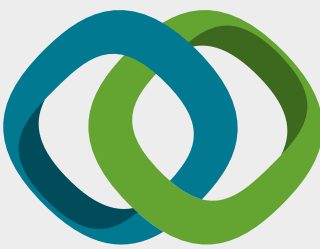

\section{Hindawi}

Submit your manuscripts at

www.hindawi.com
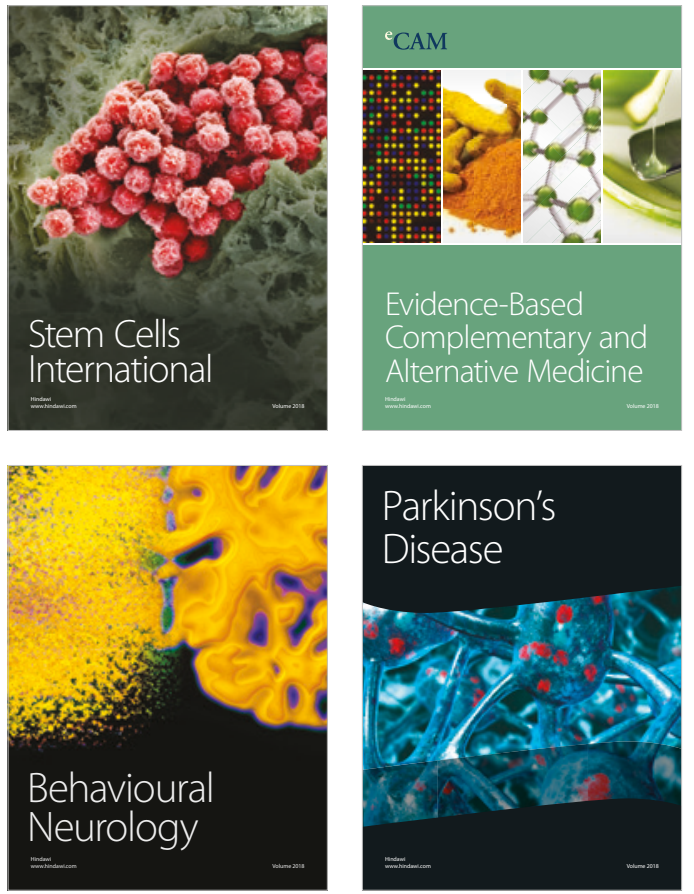

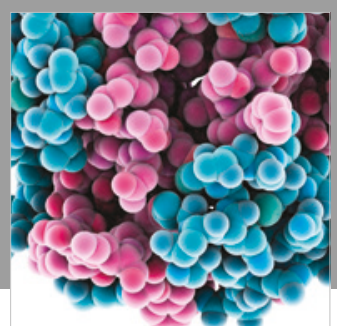

ournal of

Diabetes Research

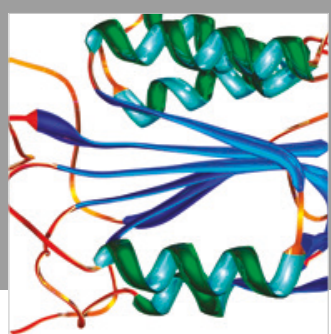

Disease Markers
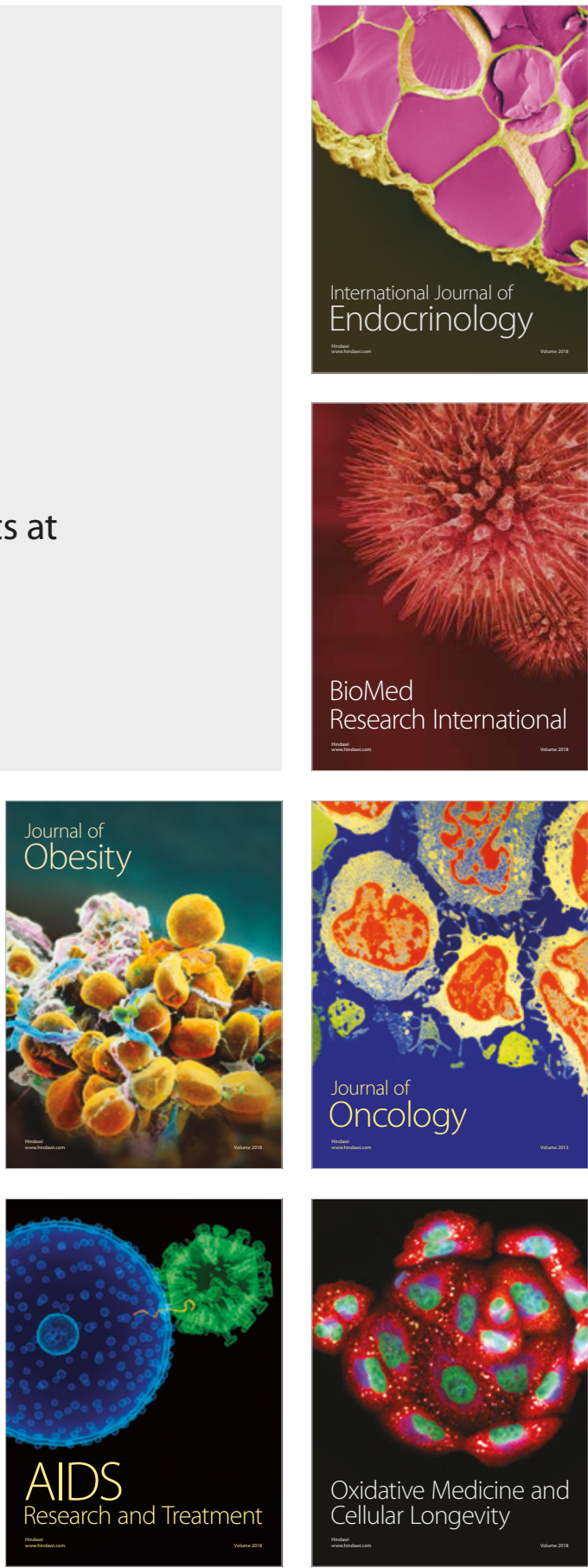